\title{
How Large is the Economy-Wide Rebound Effect?
}

\section{CAMA Working Paper 70/2020 July 2020}

\author{
David Stern \\ Arndt-Corden Department of Economics, ANU \\ Centre for Applied Macroeconomic Analysis, ANU
}

\begin{abstract}
The size of the economy-wide rebound effect is crucial for estimating the contribution that energy efficiency improvements can make to reducing greenhouse gas emissions and for understanding the drivers of energy use. Economy-wide rebound from an energy efficiency improvement includes changes in the use of energy to produce complementary and substitute goods or inputs and other flow-on effects that affect energy use across the economy as well as the direct rebound due to energy users using more of an energy service that has become less costly as result of improved energy efficiency. Jevons first argued in 1865 that improvements in energy efficiency increase total energy use, and in recent decades researchers have argued for and against this "backfire" hypothesis. Theory provides some guidance on the factors affecting rebound but does not impose much constraint on the range of possible responses. Historical evidence suggests that the improved energy efficiency of recent technology has not reduced energy use because consumption has shifted to more energy-intensive goods and services. Simulations and econometric research have produced mixed results. Some recent general equilibrium studies find large rebound, around $100 \%$, but more research is needed to confirm or refute these findings.
\end{abstract}




\title{
Keywords
}

Energy efficiency, technological change, survey, review

\author{
JEL Classification
}

Q43

\section{Address for correspondence:}

(E) cama.admin@anu.edu.au

ISSN 2206-0332

The Centre for Applied Macroeconomic Analysis in the Crawford School of Public Policy has been established to build strong links between professional macroeconomists. It provides a forum for quality macroeconomic research and discussion of policy issues between academia, government and the private sector.

The Crawford School of Public Policy is the Australian National University's public policy school, serving and influencing Australia, Asia and the Pacific through advanced policy research, graduate and executive education, and policy impact. 


\title{
How Large is the Economy-Wide Rebound Effect?
}

David I. Stern

Centre for Applied Macroeconomic Analysis and Arndt-Corden Department of Economics, Crawford School of Public Policy, The Australian National University, 132 Lennox Crossing, Acton, ACT 2601, Australia. Corresponding author: E-mail: david.stern@anu.edu.au, Telephone: +61-2-6125-0176, ORCID: 0000-0001-6595-4268

10 July 2020

\begin{abstract}
The size of the economy-wide rebound effect is crucial for estimating the contribution that energy efficiency improvements can make to reducing greenhouse gas emissions and for understanding the drivers of energy use. Economy-wide rebound from an energy efficiency improvement includes changes in the use of energy to produce complementary and substitute goods or inputs and other flow-on effects that affect energy use across the economy as well as the direct rebound due to energy users using more of an energy service that has become less costly as result of improved energy efficiency. Jevons first argued in 1865 that improvements in energy efficiency increase total energy use, and in recent decades researchers have argued for and against this "backfire" hypothesis. Theory provides some guidance on the factors affecting rebound but does not impose much constraint on the range of possible responses. Historical evidence suggests that the improved energy efficiency of recent technology has not reduced energy use because consumption has shifted to more energy-intensive goods and services. Simulations and econometric research have produced mixed results. Some recent general equilibrium studies find large rebound, around $100 \%$, but more research is needed to confirm or refute these findings.
\end{abstract}

Keywords: Energy efficiency, technological change, survey, review

JEL Codes: Q43

Acknowledgements: I thank the Australian Research Council for funding under Discovery Project DP160100756: "Energy Efficiency Innovation, Diffusion and the Rebound Effect." I thank the referees for their very helpful comments and suggestions. 


\section{Introduction}

Governments and international organizations are expecting energy efficiency improvements to make a major contribution to reducing greenhouse gas emissions and improving energy security (Stern, 2017). But energy savings are usually less than the potential implied by an energy efficiency improvement. The rebound effect is defined as:

$$
R=1-\frac{\text { Actual }}{\text { Potential }}
$$

where "potential" indicates the energy savings if the efficiency improvement is fully realized as reduced energy use, and "actual" is the energy savings that actually happen.

The size of this rebound effect is crucial for estimating the contribution that energy efficiency improvements can make to reducing greenhouse gas emissions as well as for understanding the drivers of energy use. Jevons (1865) was the first to address this issue, arguing that improvements in energy efficiency would increase rather than reduce energy use. The possibility that rebound is greater than $100 \%$ became known as Jevons' Paradox or backfire.

Just over a decade ago, Sorrell (2009) published a review of the evidence for Jevons' Paradox in this journal. He found that arguments for backfire were either largely rhetorical or anecdotal or based on relatively simple and restrictive models such as Saunders (1992, 2008). Empirical evidence was only "suggestive or indirect" (1467). He concluded that there was insufficient evidence to decide whether backfire was a common outcome or not, but "much of the evidence points to economy-wide rebound effects being larger than is conventionally assumed" (1466). In the last decade there have been advances in both theory and empirical evidence, which this paper reports on. We still do not have a definitive estimate of the size of the economy-wide rebound effect, but some empirical evidence suggests that it is large.

The micro-economic direct rebound effect occurs when an energy efficiency innovation reduces the cost of providing an energy service, such as heating, lighting, or transport, and, as a result, users increase the use of the service offsetting some of the energy efficiency improvement. But there are also changes in the use of complementary and substitute goods or inputs and other flow-on effects that affect energy use across the economy known as indirect rebound effects. Together these constitute the economy-wide rebound effect.

The size of the economy-wide rebound effect is controversial (Gillingham et al., 2013) and insufficiently researched (Turner, 2013). Writing in Nature, Gillingham et al. (2013) stated 
that claims that energy efficiency could lead to backfire were a distraction. Based on two papers by Barker and coauthors in this journal (Barker et al., 2007, 2009) they argued that economy-wide rebound was at most $60 \%$.

Theory shows that partial equilibrium (where all prices are constant) rebound is higher the higher is the elasticity of substitution between energy and other inputs (Saunders, 2008; Lemoine, 2020). General equilibrium effects could increase or decrease this rebound even resulting in "super-conservation" or negative rebound where energy use falls by more than the efficiency improvement. As an example of a general equilibrium effect, Gillingham et al. (2016) and Borenstein (2015) argue that the price of energy should fall due to the demand for energy falling as a result of the efficiency improvement, increasing rebound.

Existing estimates of the economy-wide rebound vary widely from backfire to superconservation (Saunders, 2013; Turner, 2013). The quality of quantitative estimates also varies widely. Computable general equilibrium (CGE) models are theoretically consistent but usually not very well empirically validated. Estimates of rebound from CGE models depend both on many a priori assumptions and also the parameter values used. Most econometric methods used to date are partial equilibrium approaches that do not include all mechanisms that might increase or reduce the rebound and mostly they do not credibly identify the rebound effect. However, there are a couple of recent empirically estimated or validated general equilibrium approaches (Rausch and Schwerin, 2018; Bruns et al., 2019), which find that the economy-wide rebound is around 100\%. These findings are also supported by more anecdotal economic history.

Turner (2013) notes that there is a lack of consensus in the rebound literature on what is meant by energy efficiency. Some authors include substitution of capital or materials for energy, such as the installation of insulation, in their definition of energy efficiency improvements (e.g. Sorrell et al., 2009) or examine the secondary changes resulting from an initial behavioral energy conserving action (van den Bergh, 2011). I focus on rebound effects due to energy-saving technological change. Therefore, I define energy efficiency improvements as those that save energy due to the adoption of more efficient cost-reducing technology and define the rebound effect as the resulting behavioral responses of economic agents that cause the actual energy savings to differ from the potential energy savings. ${ }^{1}$ The

\footnotetext{
${ }^{1}$ In the face of a costly energy efficiency mandate, while leaving energy efficiency unchanged.
} 
majority of studies reviewed in this survey look at efficiency improvements in industry or a non-specific economy-wide efficiency improvement. Borenstein (2015) instead looks at household energy efficiency improvements.

My emphasis on cost-reducing innovations means that this paper does not address what will happen as a result of the imposition of costly energy efficiency policies. Fullerton and Ta (2019) analyze the effects of an increase in the stringency of a consumer energy efficiency standard in a static general equilibrium model. Using plausible parameter values, they show that the total rebound from increased stringency of a costly efficiency mandate is negative, saving more energy than mandated. They also show how in the face of a pre-existing binding energy efficiency standard a cost-reducing technology shock will reduce the cost of compliance, negating the potential direct energy savings, and leaving only the positive rebound effect on energy use, resulting in backfire.

The next section of this paper reviews the body of theoretical work on the economy-wide rebound effect. The following sections review the quantitative research, which is divided between historical, accounting, computational, and econometric approaches. Finally, I provide some conclusions.

\section{Theory}

The partial equilibrium direct rebound effect was defined in the Introduction. Partial equilibrium indirect rebound effects include the energy use effects of the increase in demand for complementary energy services (and reduction in demand for substitutes) and the increase in the use of energy to produce other complementary goods and services (and reduction in energy use for the production of substitutes). These effects can also be apportioned to substitution and income or output effects for consumer energy efficiency improvements or for innovations in industry, respectively. General equilibrium and macroeconomic effects include the effect of reduced energy prices due to the fall in energy demand assuming rebound is less than 100\% (Borenstein, 2015; Gillingham et al., 2016); the effect of changes in the prices of other goods and inputs, such as wages (Lemoine, 2020); and the effects of increased total factor productivity, which increases capital accumulation and economic growth and, as a result, energy use (Saunders, 1992). Different authors classify these effects differently but everything except partial equilibrium direct rebound can usefully be thought of as indirect rebound. The total resulting change in energy use defines the economy-wide rebound effect. 
Estimates of the size of the direct rebound effect tend to be modest, positive numbers (Sorrell et al., 2009). It is usually assumed that indirect rebound is positive and that the economywide rebound will be larger in the long run than in the short run (Saunders, 2008). Turner (2013) argues, instead, that because the energy used to produce a dollar's worth of energy is higher than the embodied energy in most other goods, the effect of consumers shifting spending to goods other than energy will mean that the indirect rebound could be negative and the economy-wide rebound may also be negative. Turner (2013) also suggests that disinvestment in energy supply in response to a fall in energy demand can reduce long-run rebound compared to short-run rebound. Lemoine (2020) shows that super-conservation is possible if the elasticity of substitution between energy and other inputs in the production sector where the efficiency improvement occurs is small and the energy supply sector is energy intensive. This is because both the energy used to produce energy and the energy used in final production are reduced a lot.

Gillingham et al. (2016) define macroeconomic effects to include price and growth effects. They estimate that the price effect could contribute $20-30 \%$ of rebound. Both they and Borenstein (2015) assume that the energy supply curve is given exogenously and is upward sloping. Gillingham et al.'s (2016) growth effects include the effects of reallocation of resources across sectors due to changes in the relative returns of industries, induced innovation and its effects, and employment of previously idle resources. Measuring these growth effects is, however, challenging. The size of reallocation effects depends on elasticities of substitution in consumption and production. The more substitutable goods and inputs are, the greater the contribution to rebound will be. They argue that substitutability is low, so that macroeconomic growth effects are small.

Saunders $(1992,2008)$ provides a partial equilibrium analysis of economy-wide rebound based on the setting of the Solow (1956) growth model. He assumes a single aggregate output, that the price of energy is fixed, that the quantity of labor is fixed or grows exogenously so that its price is endogenous, and that in the short run capital is fixed, but in the long run the price of capital is fixed. There is factor-augmenting technical change. Output is given by $Y=f\left(K, A_{L} L, A_{E} E\right)$, where $K$ is capital and $A_{L} L$ and $A_{E} E$ are the effective units of labor, $L$, and energy, $E$, respectively. An increase in energy efficiency is modeled as an increase in energy's factor augmentation index, $A_{E}$. Rebound can then be written: 


$$
R=1+\frac{\partial \ln E}{\partial \ln A_{E}}
$$

For a constant elasticity of substitution (CES) production function in energy and a capitallabor aggregate, short-run rebound is:

$$
R_{S R}=\frac{\sigma}{1-S_{E}}
$$

where $\sigma$ is the elasticity of substitution between energy and capital-labor and $S_{E}$ is the cost share of energy. ${ }^{2}$ In the long run, the rebound, $R_{L R}$, is $\frac{S_{E}+S_{L}+(\sigma-1)(1-\alpha)}{S_{L}}$, where $S_{L}$ is the cost share of labor and $\alpha$ is the output elasticity of capital in the capital-labor aggregate. In both the short run and long run, the effect on energy intensity, $\sigma-1$, is the same. In the long run, the effect on output of the improvement in energy efficiency is a bit larger and so is the rebound effect. Intuitively, this is because capital expands in the long run and with it output and energy use. There is no consensus on the value of $\sigma$, though some research (Koetse et al., 2008; Stern and Kander, 2012) shows it could be between 0.6 and 1, and so rebound could be quite large. For example, if $\sigma=0.7, S_{E}=0.1$, and $S_{L}=0.6, R_{L R} \cong 0.83$.

By contrast, Lemoine (2020) assumes an arbitrary number of sectors producing distinct consumption goods as well as an energy production sector and conducts a general equilibrium analysis of the rebound effect. Each sector produces its consumption good using energy and labor and a CES technology. Lemoine (2020, Equation 16) breaks the elasticity of energy use with respect to a technology improvement in the energy augmentation index, $A_{E, k}$, of a consumption sector $k^{3}$ into the following effects:

$$
\begin{gathered}
\frac{\partial E}{\partial A_{E, k}} \frac{A_{E, k}}{E}=\text { Energy supply amplifier } \times \text { Energy supply dampener } \times \\
(P E \text { effect }+ \text { Output price effect }+ \text { Labor supply effect }+ \text { Wage effect })
\end{gathered}
$$

\footnotetext{
${ }^{2}$ The production function is $Y=\left(\gamma\left(A_{E} E\right)^{\Phi}+(1-\gamma) X^{\phi}\right)^{1 / \Phi}$, where $\mathrm{X}$ is the other input and $\phi=\frac{\sigma-1}{\sigma}$. The first order condition for minimizing cost with respect to energy use is $p_{E}-$ $\frac{\partial Y}{\partial E}=0$. Then using the implicit function theorem on this condition: $\frac{\partial E}{\partial A_{E}} \frac{A_{E}}{E}=-\frac{A_{E}}{E} \frac{\frac{\partial^{2} Y}{\partial E \partial A_{E}}}{\frac{\partial^{2} Y}{\partial E^{2}}}=$ $\frac{\sigma-1+\frac{\partial Y}{\partial A_{E}}\left(\frac{A_{E}}{Y}\right)}{1-\frac{\partial Y}{\partial E}\left(\frac{E}{Y}\right)}$. Under cost minimization $\frac{\partial Y}{\partial A_{E}} \frac{A_{E}}{Y}=\frac{\partial Y}{\partial E} \frac{E}{Y}=S_{E}$ resulting in (3).

${ }^{3}$ For the energy supply sector, a "resource supply effect" replaces the "output price effect".
} 
Rebound is then defined as $1+\frac{\partial \ln E}{\partial \ln A_{E, k}} \frac{E}{E_{k}}$, where $E$ is economy-wide energy use and $E_{k}$ is energy use in sector $k$. In the formula, "PE effect" is the elasticity of sectoral energy use with respect to an energy efficiency improvement in sector $k$, assuming all prices are constant, multiplied by its share in the physical energy use of the economy. It, therefore, reflects only direct rebound. The output price effect captures the effect of the decline in the price of the sector output due to the productivity improvement. The labor supply and wage effects reflect how induced changes in labor quantity and price affect the demand for energy through changes in the consumption of all goods and changes in the cost of production.

The common (across all goods) elasticity of substitution in consumption, $\epsilon$, turns out to also be critical to the size of the rebound effect. The signs of the last three terms depend on the values of $\epsilon$ and the elasticity of substitution in production in sector $k, \sigma_{k}$. If $\epsilon>\sigma_{k}$, the output price effect increases energy use. The labor supply effect increases energy use if labor use increases. If this effect is sufficiently large and $\epsilon>\sigma_{k}$, the combined effect of the labor supply and wage effect is to increase energy use. However, with limited labor response these effects oppose the output price effect. Then the output price effect dominates when the sector has a relatively large share in energy use but a small share in labor use. The signs of all three terms reverse if $\epsilon<\sigma_{k}$. In summary, the central case, assuming a weak labor response, is that these general equilibrium effects increase energy use relative to the partial equilibrium direct rebound effect for energy intensive sectors and reduce it for labor intensive sectors.

The "energy supply amplifier" is greater than one and is larger the larger the share of the energy supply sector in total energy use. It reflects the changes in energy use in the energy supply sector due to changes in energy requirements in the consumption goods sectors. When rebound from the other terms is less than one, it will reduce rebound. The energy supply dampener is usually less than one and reflects the effects of the energy sector on labor use. In contrast to the macro price effect in Gillingham et al. (2016), reduced energy use stemming from a consumption good sector efficiency improvement does not lower the price of energy. Instead, the price of energy is a positive linear function of the wage rate (Lemoine, 2020, Equation 6). This is because, with constant returns to scale in production, the marginal cost function (Lemoine, 2020, Equation 5) is infinitely elastic in the output of energy, while an increase in the wage rate raises the marginal cost curve. Gillingham et al. (2016) assume that the energy supply curve is upward sloping. 
For the energy sector itself, some of the terms in parentheses in the equation paralleling (4) are different. Lemoine finds that high rebound and even backfire are likely because the efficiency improvement in this sector reduces the price of energy.

Rausch and Schwerin (2018) build a single sector general equilibrium growth model using the putty-clay model, where once a capital vintage is chosen, no substitutability between energy and capital is possible. In the long run, however, energy and capital have a CobbDouglas relationship. The energy efficiency - energy services per unit energy - of energyusing capital vintages is chosen depending on the relative price of capital to energy at the time of investment. The capital price is the effectiveness of investment in creating capital technical change reduces the cost of creating capital from final output. The price of energy is seen as the exogenous cost of supplying energy. Therefore, they do not distinguish between energy-capital substitution and energy-augmenting technical change. They find that a fall in the energy-using capital price increases energy use. Therefore, this model implies backfire from this source of increased energy efficiency regardless of parameter values. On the other hand, an increase in the price of energy reduces energy use, as we would expect.

As we can see, theory provides insights on the mechanisms that drive economy-wide rebound but is not especially helpful in estimating how large the rebound really is. We, therefore, turn to quantitative evidence.

\section{Historical Evidence}

Historical research hints that the economy-wide rebound effect could be large. Both van Benthem (2015) and Csereklyei et al. (2016) find that though energy intensity declines with increased income, energy intensity in developing countries today is similar to what it was in today's developed countries when they were at similar income levels. But, van Benthem (2015) argues that the energy efficiency of many products currently sold in developing countries is much better than that of comparable products sold in developed countries when they were at the same income level. He finds that energy savings from access to more efficient technologies have been offset by other trends, including a shift toward more energyintensive consumption bundles and compositional changes in industry such as outsourcing. Though such studies cannot identify causal effects, they suggest that the economy-wide rebound effect is close to $100 \%$. 
Hart (2018) argues that if aggregate energy intensity has improved less than the improvement in efficiency at the product or process level, this must mean that there has been a shift in consumption towards more energy-intensive goods. The question is: to what degree has this been driven by income effects - it just happens that more luxurious goods are also more energy intensive - or by substitution effects so that increased energy efficiency ${ }^{4}$ has resulted in substitution towards more energy intensive goods?

Hart (2018) provides a theoretical model of this shift to more energy intensive goods. He assumes that the elasticity of substitution between energy and labor in production is zero but that consumer preferences are non-homothetic and no good is essential. Energy has widely varying productivity in producing the range of consumption goods. By contrast, labor productivity (labor-augmenting technology) is equal across all goods. This means that the most energy-intensive goods are the most expensive. Rising income means consumers will consume more of the more energy intensive goods, while growth in energy productivity will lower the costs of the most energy-intensive goods most. This seems to explain the historical patterns of change quite well. Hart parameterizes this model using a mix of data from developed economies. Based on this, rebound is 50\% and the remaining gap between change in energy intensity and change in energy efficiency is explained by income effects.

Tsao et al. (2010) showed that expenditure on lighting had been a constant share of GDP over three centuries despite huge gains in luminous efficacy. If the income elasticity of lighting services is one and the fall in the price of lighting services is entirely explained by improving energy efficiency, then the rebound effect is $100 \%$. Of course, as Saunders and Tsao (2012) point out, this does not include any indirect rebound effects and so is not a measure of economy-wide rebound. However, it shows the potential for high rebound for (formerly?) energy intensive goods and services.

\section{Accounting Approaches}

The "economic accounting approach" has been used by several researchers (e.g. Shao et al., 2014; Lin and Du, 2015; Zhang and Lin-Lawell, 2017) to estimate the economy-wide rebound for China. It amounts to estimating the rebound as the ratio of the TFP growth rate and the energy productivity (inverse of energy intensity) growth rate. This is based on

\footnotetext{
${ }^{4}$ Hart (2018) notes that if labor-augmenting technical change is more rapid in more energy intensive sectors then it might not be energy efficiency improvements that are driving this substitution.
} 
assuming that the change in energy intensity is equivalent to the change in energy efficiency and that the growth rate of energy use due to output expansion resulting from the energy efficiency improvement is equal to the rate of TFP growth.

There is no reason to assume the latter, but other researchers may also be tempted to use energy intensity as a measure of energy efficiency. So, it is important to explain why this is not a good approach. First, there are many reasons why energy intensity might change (Ang, 2006). Second, changes in energy intensity already incorporate the majority of the rebound effect to changes in energy efficiency. Following Saunders (2008), we can express energy use, $E$, as the identity $E \equiv \frac{E}{Y} Y$, where $Y$ is aggregate output, and $E / Y$ is energy intensity. Taking logs and differentiating with respect to energy efficiency, $A_{E}$, we have:

$$
\frac{\partial \ln E}{\partial \ln A_{E}}=\frac{\partial \ln (E / Y)}{\partial \ln A_{E}}+\frac{\partial \ln Y}{\partial \ln A_{E}}
$$

The first term on the right-hand side is the elasticity of energy intensity with respect to energy efficiency and the second is the output elasticity. Rebound is given by (2). In Saunders' (2008) short-run partial equilibrium context, $\frac{\partial \ln (E / Y)}{\partial \ln A_{E}}=\sigma-1$ and if output is held constant the rebound is then $\sigma$. Allowing output to vary, $\frac{\partial \ln Y}{\partial \ln A_{E}}=\frac{\sigma S_{E}}{1-S_{E}}$, and the total rebound will be $\frac{\sigma}{1-S_{E}}$, as in (3). As long as $S_{E}<0.5$, the contribution of the intensity effect to rebound will be greater than the contribution of the output effect. In fact, $S_{E}$ is likely to be 0.1 or less in developed economies. So, studies which treat the change in energy intensity as their measure of the change in energy efficiency will probably miss most of the rebound effect.

Galvin (2014) uses a different accounting approach. He compares estimates of household energy efficiency improvement from the EU's Odyssee database with the actual development of household energy use to estimate an overall "broad-brush" rebound of $18 \%$. This nicely identifies energy efficiency improvements but not their effect on energy use, which as the paper notes may be determined by many factors including income and the price of energy. It also does not include broader economy-wide changes.

\section{Computational Approaches}

In this section, I review structural models that are not fully econometrically estimated. The most straightforward approach is to use relatively simple analytically tractable structural 
models of the economy such as the partial equilibrium approaches proposed by Saunders $(1992,2008)$ and the general equilibrium approach proposed by Lemoine (2020), that we have already discussed..$^{5}$ Analytical formulae for the rebound effect are derived and rebound calculated based on parameter values mostly derived from other studies. Saunders (2015) argues based on high estimates of the elasticity of substitution between energy and other inputs that rebound is large.

Lemoine (2020) uses his general equilibrium framework to carry out a quantitative analysis using U.S. parameter values, and assuming that $\epsilon=0.9$ and that labor supply is fixed. He finds that for a general energy efficiency improvement across all sectors the rebound is $38 \%$. The "partial equilibrium effect" would be $40 \%$. In this example, the output effect increases and the wage effect slightly decreases the rebound, while the combined energy supply amplifier and dampener is 1.2, which has the effect of reducing energy use more and so reducing the rebound. On the other hand, efficiency improvements in the energy supply sector can have especially large rebound. For an efficiency improvement in this sector alone, rebound is estimated at $80 \%$.

These methods depend on having good estimates of the production parameters - a notoriously difficult problem (Leon-Ledesma et al., 2010; Ma and Stern, 2016). Better estimates can be obtained by exploiting the first-order optimization conditions and using methods designed for estimating long run relationships. Lemoine (2020) uses parameters estimated by Koesler and Schymura (2015). Their approach only uses production function equations, assumes that technical change is Hicks neutral, and does not use a specifically long-run estimation approach. The estimated elasticities are mostly low but the variance across sectors is high. The elasticities of substitution in production in Lemoine's empirical analysis are relatively small with a mean and median elasticity of 0.33 and 0.25 . Larger elasticities would mean a greater rebound.

Chitnis and Sorell (2015) estimate total rebound for household efficiency improvements in the UK. They attempt to capture both the income and substitution effects of energy efficiency improvements as well as the implications for energy use across the economy. They estimate a

${ }^{5}$ Saunders (2013) also proposed estimating a translog cost function and first order conditions with factor augmenting technical change and using this model to conduct historical and counterfactual simulations. However, as he notes, this only considers the direct rebound effects and so is not discussed further here. 
household demand model to obtain price and expenditure elasticities of different goods and services and use a multiregional input-output model to estimate the GHG emission intensities of those goods and services. They estimate that the total rebound effects are $41 \%$ for measures that improve the efficiency of domestic gas use, $48 \%$ for electricity use and $78 \%$ for vehicle fuel use. This study does not include general equilibrium effects but is a sensible approach to obtaining the partial equilibrium effect.

Computable general equilibrium models use a simulation of a system of equations to estimate the economy-wide change in energy use for an improvement of energy efficiency either in a single sector or across the economy (e.g. Turner, 2009; Barker et al., 2009; Turner and Hanley, 2011; Broberg et al., 2015; Koesler et al., 2016; Lu et al., 2017; Wei and Liu, 2017). Using a Post-Keynesian global model, Barker et al. (2009) estimated the rebound from a set of IEA recommended energy efficiency policies globally at 50\%. Using a more conventional CGE model, Koesler et al. (2016) similarly estimated the global rebound from energy efficiency improvements in German production at 47\%. However, Turner (2009) finds that, depending on the assumed values of the parameters in a CGE model, the rebound effect for the UK can range from negative to more than $100 \%$. CGE results also critically depend on parameter values and so do not provide very strong evidence on the size of the economy-wide rebound effect.

Rausch and Schwerin (2018) also calibrate their model, which was discussed in the theory section above, on U.S. annual data from 1960 to 2011. In terms of complexity this is midway between the CGE models and analytically tractable models and is better empirically validated than most studies. Rebound to energy efficiency improvements depends on the contributions of energy and capital prices to realized energy efficiency and on parameter values. Superconservation is possible if energy efficiency improvement is driven by rising energy costs. They compare the historical simulation to a counterfactual scenario with no energy efficiency improvements by holding energy and energy-using capital prices constant, finding a rebound of $102 \%$. This is because the declining cost of capital dominates increasing energy prices.

\section{Econometric Evidence}

In this section, I review models that are fully econometrically estimated and derive the rebound from the estimated model. Several methods have been proposed to econometrically estimate the economy-wide rebound effect (e.g. Orea et al., 2015; Adetutu et al., 2016; Bruns et al., 2019). 
Orea et al. (2015) estimate an energy demand function with stochastic frontier energy efficiency terms. The purely stochastic inefficiency term is multiplied by $\left[1-R\left(\gamma^{\prime} z\right)\right]$ where $\mathrm{z}$ is a vector of variables including GDP per capita, the price of energy, and average household size. $R\left(\gamma^{\prime} z\right)$ is then supposed to be an estimate of the rebound effect. But really this is just a reformulation of the inefficiency term - nothing specifically identifies $R\left(\gamma^{\prime} z\right)$ as the rebound effect. Also, as energy price and income are controlled for, it is a partial equilibrium approach.

Adetutu et al. (2016) use a stochastic frontier model to estimate energy efficiency and then a dynamic panel model to estimate the effect of efficiency on energy use. Here, it is somewhat plausible that the changes in efficiency are independent of the other variables in the model so that they estimate a causal effect, which is needed to claim a rebound effect (Gillingham et al., 2016). However, the efficiency term for the input distance function reflects the efficiency of the use of all inputs, not just energy. As the dynamic analysis controls for energy prices and output this is a partial equilibrium estimate.

They estimate that in the short run rebound is $90 \%$ while in the long run super-conservation occurs with a negative rebound of $36 \%$. According to Le Châtelier's principle, we would generally expect more flexibility in the long run than the short run (Milgrom and Roberts, 1996) so that energy use would rebound more. Turner $(2009,2013)$ argued for long-run rebound to be smaller than short-run, but the extent of the switch-around here is surprising. This is a result of the specification of the dynamic regression model. The long-run elasticity of energy with respect to energy efficiency, $\eta_{L R}$, is given by:

$$
\eta_{L R}=\frac{\eta_{S R}}{1-\rho}
$$

where $\eta_{S R}$ is the short-run elasticity and $1>\rho>0$ is the regression coefficient of lagged log energy use. If $\eta_{S R}<0$ then $\eta_{L R}<\eta_{S R}$ and the long-run rebound effect will be smaller and possibly negative. The estimate of $\rho$ is 0.923 and, therefore, $\eta_{L R} \cong 13 \eta_{S R}$.

In a recent working paper, Bruns et al. (2019) lay out an approach to estimating the economywide rebound using structural vector autoregression models that attempts to include general equilibrium effects and define exogenous shocks to energy efficiency. 
They model the vector of aggregate energy use, the price of energy, and gross domestic product (GDP) as the outcome of cumulative shocks to GDP, the price of energy, and a residual energy-specific shock:

$$
x_{t}=\mu+\sum_{i=1}^{p} \Pi_{i} x_{t-i}+B \varepsilon_{t}
$$

where $x_{t}=\left[e_{t}, p_{t}, y_{t}\right]^{\prime}$ is the vector of the logs of energy use, the price of energy, and GDP, respectively, observed in period $t . \varepsilon_{t}=\left[\varepsilon_{e t}, \varepsilon_{p t}, \varepsilon_{y t}\right]^{\prime}$ is the vector of exogenous shocks with $\operatorname{var}\left(\varepsilon_{t}\right)=I, \mu$ is a vector of constants, and $B$ and the $\Pi_{i}$ are matrices of parameters to be estimated. They interpret $\varepsilon_{e t}$ as an energy efficiency shock, as it represents the exogenous reduction in energy use that is not due to exogenous shocks to GDP or energy prices and previous changes in those variables themselves. The mixing matrix, $B$, transmits the effect of the shocks to the dependent variables. Therefore, each of the shocks can have immediate effects on each of the variables. The matrix $B$ is estimated and hence the shocks are identified using independent component analysis based on the distance covariance criterion (Matteson and Tsay, 2017). ${ }^{6}$

Bruns et al. (2019) then use the impulse response function of energy with respect to the energy efficiency shock to measure the rebound effect. Using the subscript $i$ to denote the number of periods since the energy efficiency improvement, the rebound effect is given by:

$$
R_{i}=1-\frac{\Delta \hat{e}_{i}}{\varepsilon_{e 1}}=1-\frac{\text { Actual }}{\text { Potential }}
$$

where $\varepsilon_{e 1}$ the energy efficiency shock in the initial period that represents the potential "engineering" change in log energy use, $e$, and $\Delta \hat{e}_{i}$ is the actual change in log energy use due to the shock as given by the impulse response function. They argue that this is a general equilibrium measure of rebound because the price of energy and the level of output can evolve in response to the energy efficiency shock.

\footnotetext{
${ }^{6}$ The paper also uses several other algorithms and model specifications.
} 

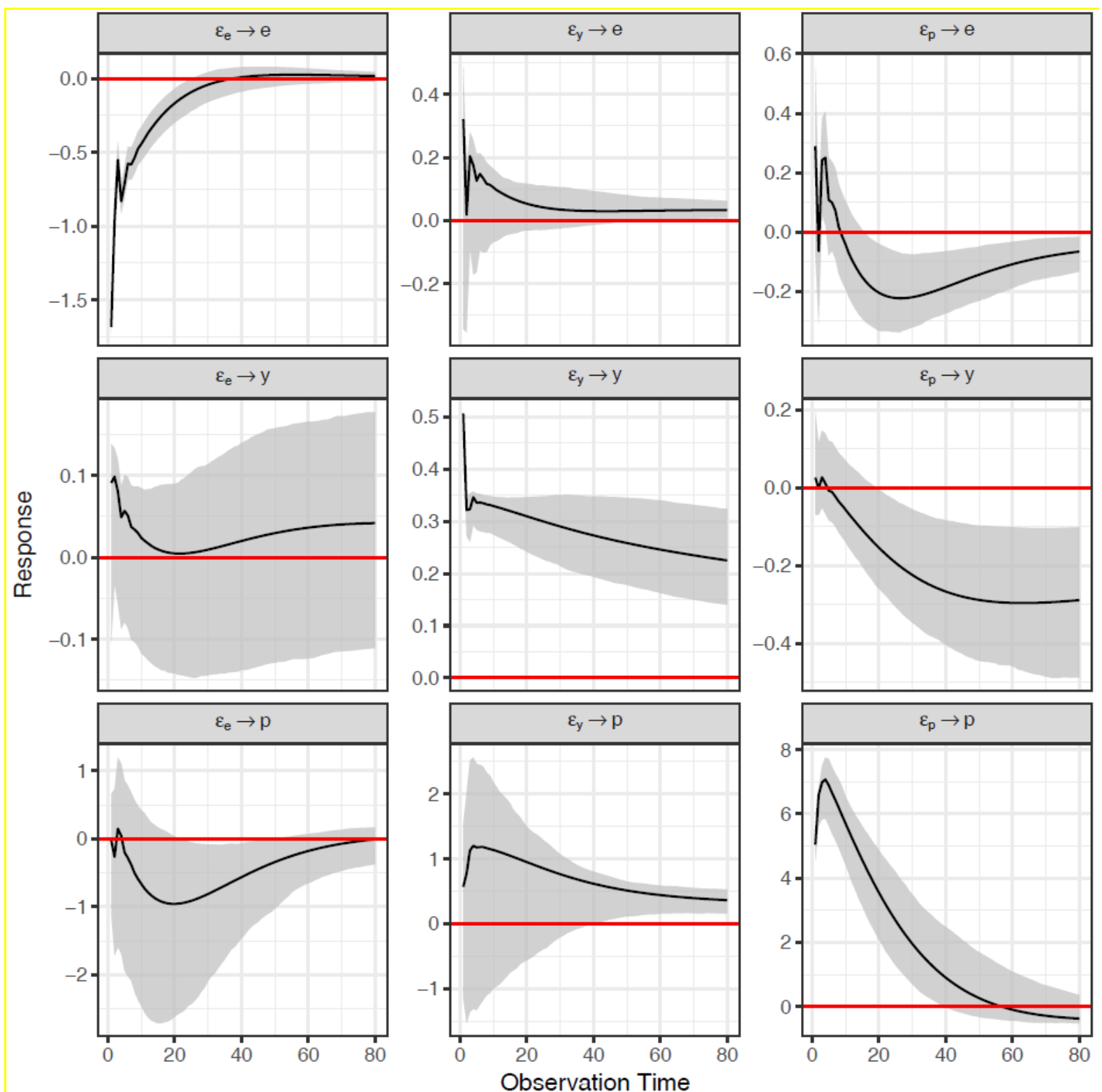

Figure 1. Impulse Response Functions for U.S. Monthly Data: Grey shading is a $90 \%$ confidence interval computed using the wild bootstrap with 1000 iterations. $\varepsilon_{e}$, $\varepsilon_{y}$, and $\varepsilon_{p}$ are the energy, GDP, and energy price shocks, respectively which drive changes in energy use, $e$, GDP, $y$, and the price of energy, $p$. All variables are in natural logarithms. Source: Bruns et al. (2019).

Figure 1 shows the impulse response functions for an SVAR estimated by Bruns et al. using U.S. monthly data from 1992 to 2016. The first column shows the effect of the energy efficiency shock on energy use, GDP, and the energy price. The energy efficiency shock results in a strong decrease in energy use initially, but this effect is eliminated over time, resulting in no savings in energy use. We would expect an energy efficiency shock to raise GDP as it contributes to GDP. If energy demand falls as a result of the shock it should also lower the price of energy. We see these effects in the first column of Figure 1, though the confidence intervals mostly include zero. 
A GDP shock that raises GDP should increase demand for energy raising its quantity and price. The second column of the figure shows these effects. Finally, an energy price shock should lower energy use and GDP. We also see that though the initial effect of the price shock on energy use and GDP is positive (but not statistically significant); in the longer run it has the expected negative and statistically significant effects on both variables. In contrast, the price shock appears to have transitory effects on the price of energy but what look like permanent effects on at least GDP. The long-run effects, therefore, conform with standard economic theory.

\section{Conclusion and Policy Implications}

Despite much research on this topic, we do not have a definitive answer to the question in the title of this paper. Theory provides much insight on potential rebound mechanisms, but directly translating theoretical models into quantitative estimates depends on elusive estimates of parameters and assumptions about the nature of technological change and energy supply.

While earlier research emphasized the role of the elasticity of substitution in production between energy and other inputs, recent research finds that substitutability in consumption is also critical. Understanding how the energy supply sector interacts with other effects to increase or reduce the rebound is also central to understanding the potential size of the rebound. The nature of technological change is also important. For example, a putty-clay model is relatively predisposed to finding large rebound.

Historical evidence is intriguing and suggests that the rebound is large, though such evidence does not explicitly control for other factors. This research suggests that consumers have shifted to more energy intensive consumption goods over time as energy efficiency improvements have reduced their cost. Hart (2018) parameterizes such a model and shows the effect could be large.

Computational approaches to estimating the rebound provide a range of values, typically between 50 and $100 \%$ but sometimes lower or higher. Like more theoretical approaches, they depend on parameter values and model structure. There are only a few truly econometric studies of the economy-wide rebound using stochastic frontier models or VARs to derive energy efficiency changes. Bruns et al. (2019) estimate that the rebound is around $100 \%$ in the US economy, which is similar to that estimated by Rausch and Schwerin (2018) whose 
calibration of a general equilibrium model is probably the most credible to date. It is easy, however, to question whether both these papers have actually identified an energy efficiency improvement. In putty-clay models, changes in energy and capital prices determine changes in energy efficiency and there is no substitution between energy and capital once capital is installed. On the other hand, many are skeptical of data-driven macroeconomic time series research such as Bruns et al. (2019). In my opinion, building on these approaches is likely to be the most fruitful direction for future empirical research. Such a model would use less restrictive assumptions than Rausch and Schwerin (2018) but more restrictive assumptions than data-driven models like Bruns et al. (2019).

Policymakers should be cautious about advocating energy efficiency innovation as a climate change solution. Stern (2017) finds that the IEA's recent predictions of future changes in energy intensity have so far overestimated the actual decline in energy intensity. Saunders (2013) argues that this is because such models tend to underestimate rebound. As we have seen, there is evidence for possible large rebound or even backfire in the empirical literature and Fullerton and Ta (2018) show that pre-existing energy efficiency standards can exacerbate backfire from energy efficiency innovation. On the other hand, increasing the stringency of costly efficiency mandates could have large energy-saving effects.

\section{References}

Adetutu, M. O., Glass, A. J., Weyman-Jones, T. G., 2016. Economy-wide estimates of rebound effects: Evidence from panel data. Energy Journal 37(3), 251-269.

Ang, B. W., 2006. Monitoring changes in economy-wide energy efficiency: From energy-GDP ratio to composite efficiency index. Energy Policy 34(5), 574-582.

Barker, T., Ekins, P., Foxon, T., 2007. The macro-economic rebound effect and the UK economy. Energy Policy 35(10), 4935-4946.

Barker, T., Dagoumas, A., Rubin, J., 2009. The macroeconomic rebound effect and the world economy. Energy Efficiency 2, 411-427.

Borenstein, S., 2015. A microeconomic framework for evaluating energy efficiency rebound and some implications. Energy Journal 36(1), 1-21. 
Broberg, T., Berg, C. and Samakovlis, E., 2015. The economy-wide rebound effect from improved energy efficiency in Swedish industries-A general equilibrium analysis. Energy Policy 83, 26-37.

Bruns S. B., Moneta, A., Stern, D. I., 2019. Estimating the economy-wide rebound effect using empirically identified structural vector autoregressions. LEM Working Paper Series 2019/27.

Chitnis, M., Sorrell, S., 2015. Living up to expectations: Estimating direct and indirect rebound effects for UK households. Energy Economics 52, S100-S116.

Csereklyei, Z., Rubio Varas, M. d. M., Stern, D. I., 2016. Energy and economic growth: The stylized facts. Energy Journal 37(2), 223-255.

Fullerton, D., Ta, C. L., 2019. Costs of energy efficiency mandates can reverse the sign of rebound. National Bureau of Economic Research Working Paper 25696.

Galvin, R., 2014. Estimating broad-brush rebound effects for household energy consumption in the EU28 countries and Norway: some policy implications of Odyssee data. Energy Policy $73,323-332$.

Gillingham, K, Kotchen, M. J., Rapson, D., Wagner, G., 2013. The rebound effect is overplayed. Nature 493, 475-476.

Gillingham, K., Rapson, D., Wagner, G., 2016. The rebound effect and energy efficiency policy. Review of Environmental Economics and Policy 10(1), 68-88.

Hart, R., 2018. Rebound, directed technological change, and aggregate demand for energy. Journal of Environmental Economics and Management 89, 1-17.

Jevons, W. S., 1865. The coal question: an inquiry concerning the progress of the nation, and the probable exhaustion of our coal-mines. London: Macmillan.

Koesler, S., Schymura, M., 2015. Substitution elasticities in a constant elasticity of substitution framework-empirical estimates using nonlinear least squares. Economic Systems Research 27(1), 101-121.

Koesler, S., Swales, K., Turner, K., 2016. International spillover and rebound effects from increased energy efficiency in Germany. Energy Economics 54, 444-452. 
Koetse, M. J., De Groot, H. L., Florax, R. J., 2008. Capital-energy substitution and shifts in factor demand: A meta-analysis. Energy Economics 30(5), 2236-2251.

Lemoine, D., 2020. General equilibrium rebound from energy efficiency innovation. European Economic Review 125, 103431.

Lin, B., Du, K., 2015. Measuring energy rebound effect in the Chinese economy: An economic accounting approach. Energy Economics 50, 96-104.

Lu, Y., Liu, Y., Zhou, M., 2017. Rebound effect of improved energy efficiency for different energy types: A general equilibrium analysis for China. Energy Economics 62, 248-256.

Ma C., Stern, D. I., 2016. Long-run estimates of interfuel and interfactor elasticities. Resource and Energy Economics 46, 114-130.

Matteson, D.S., Tsay, R.S., 2017. Independent component analysis via distance covariance. Journal of the American Statistical Association 112(518), 623-637.

Milgrom, P., Roberts, J., 1996. The LeChatelier Principle. American Economic Review, 86, 173-179.

Orea, L., Llorca, M., Filippini, M., 2015. A new approach to measuring the rebound effect associated to energy efficiency improvements: An application to the US residential energy demand. Energy Economics 49, 599-609.

Rausch, S., Schwerin, H., 2018. Does higher energy efficiency lower economy-wide energy use? Center of Economic Research at ETH Zurich, Economics Working Paper 18/299.

Saunders, H. D., 1992. The Khazzoom-Brookes postulate and neoclassical growth. Energy Journal 13(4), 131-148.

Saunders, H. D., 2008. Fuel conserving (and using) production functions. Energy Economics $30,2184-2235$.

Saunders, H. D., 2013. Historical evidence for energy efficiency rebound in 30 US sectors and a toolkit for rebound analysts. Technological Forecasting and Social Change 80(7), $1317-1330$.

Saunders, H. D., 2015. Recent evidence for large rebound: Elucidating the drivers and their implications for climate change models. Energy Journal 36(1), 23-48. 
Saunders, H. D., Tsao, J. Y., 2012. Rebound effects for lighting. Energy Policy 49, 477-478.

Shao, S., Huang, T., Yang, L., 2014. Using latent variable approach to estimate China's economy-wide energy rebound effect over 1954-2010. Energy Policy 72, 235-248.

Sorrell, S., 2009. Jevons' Paradox revisited: The evidence for backfire from improved energy efficiency. Energy Policy 37(4), 1456-1469.

Stern, D. I., 2017. How accurate are energy intensity projections? Climatic Change 143, 537545.

Tsao, J., Saunders, H. D., Creighton, J., Coltrin, M., Simmons, J., 2010. Solid-state lighting: an energy-economics perspective. Journal of Physics D, Applied Physics 43(35), 1-17.

Turner, K., 2009. Negative rebound and disinvestment effects in response to an improvement in energy efficiency in the UK economy. Energy Economics 31, 648-666.

Turner, K., 2013. "Rebound" effects from increased energy efficiency: a time to pause and reflect. Energy Journal 34(4), 25-43.

Turner, K. and Hanley, N., 2011. Energy efficiency, rebound effects and the environmental Kuznets Curve. Energy Economics 33(5), 709-720.

van Benthem, A. A., 2015. Energy leapfrogging. Journal of the Association of Environmental and Resource Economists 2(1), 93-132.

Wei, T. and Y. Liu (2017) Estimation of global re-bound effect caused by energy efficiency improvement. Energy Economics 66, 27-34. 